\title{
Trends in socioeconomic inequalities in smoking prevalence, consumption, initiation, and cessation between 2001 and 2008 in the Netherlands. Findings from a national population survey
}

Gera E Nagelhout ${ }^{1} 2^{2}$, Dianne de Korte-de Boer ${ }^{2}$, Anton E Kunst ${ }^{3}$, Regina M van der Meer ${ }^{1}$, Hein de Vries ${ }^{2}$, Boukje M van Gelder ${ }^{4}$ and Marc C Willemsen ${ }^{1,2}$

\begin{abstract}
Background: Widening of socioeconomic status (SES) inequalities in smoking prevalence has occurred in several Western countries from the mid 1970's onwards. However, little is known about a widening of SES inequalities in smoking consumption, initiation and cessation.

Methods: Repeated cross-sectional population surveys from 2001 to 2008 ( $n \approx 18,000$ per year) were used to examine changes in smoking prevalence, smoking consumption (number of cigarettes per day), initiation ratios (ratio of ever smokers to all respondents), and quit ratios (ratio of former smokers to ever smokers) in the Netherlands. Education level and income level were used as indicators of SES and results were reported separately for men and women.

Results: Lower educated respondents were significantly more likely to be smokers, smoked more cigarettes per day, had higher initiation ratios, and had lower quit ratios than higher educated respondents. Income inequalities were smaller than educational inequalities and were not all significant, but were in the same direction as educational inequalities. Among women, educational inequalities widened significantly between 2001 and 2008 for smoking prevalence, smoking initiation, and smoking cessation. Among low educated women, smoking prevalence remained stable between 2001 and 2008 because both the initiation and quit ratio increased significantly. Among moderate and high educated women, smoking prevalence decreased significantly because initiation ratios remained constant, while quit ratios increased significantly. Among men, educational inequalities widened significantly between 2001 and 2008 for smoking consumption only.
\end{abstract}

Conclusions: While inequalities in smoking prevalence were stable among Dutch men, they increased among women, due to widening inequalities in both smoking cessation and initiation. Both components should be addressed in equity-oriented tobacco control policies.

Keywords: Netherlands, Smoking, Social class, Trends

\footnotetext{
* Correspondence: gnagelhout@stivoro.nl

${ }^{1}$ STIVORO Dutch Expert Centre on Tobacco Control, PO Box 16070, 2500 BB,

The Hague, the Netherlands

${ }^{2}$ Maastricht University (CAPHRI), Maastricht, the Netherlands

Full list of author information is available at the end of the article
} 


\section{Background}

Nowadays, mortality rates tend to be higher among lower socioeconomic status (SES) groups in most Western countries [1-3]. The higher prevalence of smoking in individuals from lower SES groups is the single most important cause of socioeconomic differences in mortality $[4,5]$. The smoking epidemic model describes the trends of smoking prevalence and smoking-attributable mortality in populations over time [6]. In the first stage of the smoking epidemic, smoking prevalence and smoking-attributable mortality is low and rising. In the second stage, smoking prevalence among men rises rapidly, while smoking among women lags behind. Smoking prevalence rates are similar among different SES groups or may be higher among high SES groups. In the third stage, male prevalence declines and female prevalence remains stable. There is a rapid rise in smoking-attributable mortality among men. In the fourth stage of the smoking epidemic, smoking prevalence declines for both men and women and there is a rapid rise in smoking-attributable mortality among women. Smoking prevalence is higher among lower SES groups in this stage and a widening of SES inequalities in smoking prevalence may occur. A widening of SES inequalities in smoking has been found for several Western countries from the mid 1970's onwards, for example in most U.S. states [7,8], Canada [9], Australia [10,11], New Zealand [12], and most European countries [13-16].

Studies that examined trends in SES differences in smoking focused mostly on differences in smoking prevalence [17], i.e. the proportion of smokers in a population. These studies provide no information about how SES differences in smoking prevalence originate, because the smoking prevalence in a population is determined both by smoking initiation and by smoking cessation. The few studies that have examined trends in SES inequalities in both smoking initiation and cessation found mixed results $[8,18]$. One study found that widening SES inequalities in cessation are mostly responsible for widening SES differences in smoking prevalence [8], while the other study found that inequalities in initiation are a more important explanation [18]. Knowledge about trends in SES inequalities in initiation and cessation can potentially help to better inform future tobacco control interventions [19]. Furthermore, it is important to examine SES differences in smoking consumption levels, as consumption levels have been found to relate in a dose-response manner to the risks and severity of many smoking related diseases [20]. Therefore, information about trends in SES differences in smoking consumption, smoking initiation, and smoking cessation is required [17].

In the current study, trends in SES differences in four smoking related outcomes are examined for the Netherlands for the period 2001 to 2008. In this period, several tobacco control policies were implemented that could have influenced SES differences in smoking. In 2002, text warning labels for cigarette packages were implemented and a tobacco advertising ban was implemented [21]. In 2003, a youth access law was implemented [21]. In 2004, smoke-free workplace legislation was implemented, which was extended in 2008 so as to include the hospitality industry [22]. Tax increases were implemented in 2001, 2004, and 2008 and intensive national mass media smoking cessation campaigns ran in 2003, 2004, and 2008 [22].

We aim to answer the following research questions: 1) Were there SES differences in smoking prevalence, smoking consumption, smoking initiation, and smoking cessation in the Netherlands in 2001 and 2008? and 2) Did these SES differences change in the period 2001 to 2008? These research questions are answered for both men and women.

\section{Methods \\ Sample}

Data were obtained from the Dutch Continuous Survey of Smoking Habits (DCSSH). This is a cross-sectional population survey of respondents aged 15 years and older that is used to monitor smoking habits of the Dutch population, using weekly measurements. The DCSSH is conducted by market research company TNS NIPO for the Dutch expert centre on tobacco control (STIVORO). Respondents for the DCSSH were selected from TNS NIPObase, a database containing more than 140,000 potential respondents who participate in internet-based research on a regular basis. TNS NIPObase panel members are recruited actively by TNS NIPO using telephone and mail.

For the present study, DCSSH data from 2001 until 2008 were used. The questionnaire was sent to a stratified random sample of potential respondents by e-mail. Respondents completed the questionnaire at their own computer using software from TNS NIPO. Approximately 18,000 respondents participated in the survey each year, totaling 144,733 respondents in the period 2001 to 2008 . The respondents were representative of the Dutch population of 15 years and older after applying weights for gender, age, education level, working hours, geographic region, urbanization, and household size. Response data were weighted on the basis of stratum weights. Each respondent was provided a weight by TNS NIPO with DIANA software, using an iterative process until there was little deviation between the weighted data and the target strata.

The Central Committee on Research Involving Human Subjects in the Netherlands requires no ethical approval for non-medical survey research. 


\section{Questionnaire}

The DCSSH questionnaire assessed demographic characteristics, smoking behaviour and use of smoking cessation aids and contained sections on tobacco control policies and campaigns. For the current study, we used questions about SES indicators, smoking status, smoking consumption, age, and gender.

Although education level is seen as a key indicator of SES $[17,23]$, it has been recommended to include other indicators as well to account for other dimensions of SES that have shown to be independently related to smoking [17]. We, therefore, used both education level and income level as indicators of SES. We categorized education level into three groups: low (primary education and lower prevocational secondary education), moderate (middle prevocational secondary education and secondary vocational education) and high (senior general secondary education, (pre-)university education and higher professional education). Gross yearly household income level was also categorized into three equal sized groups: low (less than 28,500 Euro $=<25,600 \mathrm{GBP}$ ), moderate (between 28,500 and 45,000 Euro $=25,600-40,430 \mathrm{GBP}$ ), and high (more than 45,000 Euro $=>40,430 \mathrm{GBP}$ ).

In line with earlier studies [22,24], current smoking status was assessed by asking 'do you (ever) smoke or do you not smoke at all?'. Respondents who answered that they smoke were defined as current smokers. Respondents who answered that they do not smoke were asked: 'have you smoked in the past?'. Respondents who answered that they had smoked in the past were defined as former smokers and respondents who answered that they had not smoked in the past were defined as never smokers. Smoking prevalence was defined as the proportion of all respondents who were current smokers (current smokers/all respondents *100). In the regression analyses, smoking prevalence was treated as a binary outcome.

Following recommendations from Schaap and Kunst [17], smoking initiation and cessation were examined by calculating initiation ratios and quit ratios. Initiation ratio was defined as the ratio of all respondents who were ever smokers (current + former smokers/all respondents). Quit ratio was defined as the ratio of ever smokers who were former smokers (former smokers/current + former smokers). In the regression analyses, initiation and quit ratios were treated as binary outcomes.

Smoking consumption was measured by asking current smokers how many cigarettes (factory made and/or rollyour-own) they smoked on average per day. In the regression analyses, smoking consumption was treated as a continuous outcome.

Furthermore, age and gender were assessed. Age was categorized into four groups: 15-24 years, 25-39 years, $40-54$ years, and 55 years and older.

\section{Analyses}

SES differences in smoking related outcomes (research question 1) were examined by logistic regression analyses (for smoking prevalence, initiation, and cessation) and linear regression analyses (for smoking consumption). Dependent variables were smoking prevalence, smoking consumption, smoking initiation, and smoking cessation. Independent variables were education level and income level (in separate analyses). Regression analyses were controlled for age group and reported separately for men and women in 2001 and 2008. Respondents who did not report their education level $(n=665,0.5 \%)$ were excluded from the analyses with education level. Respondents who did not report their income level $(n=30,661,21.2 \%)$ were excluded from the analyses with income level. Respondents who did not report their income level were significantly more likely to have a low education level $\left(\chi^{2}(2)=413.08\right.$, $\mathrm{p}<0.001)$, to be younger ( $\mathrm{F}(1)=238.40, \mathrm{p}<0.001)$, and to be a current smoker $\left(\chi^{2}(1)=61.52, \mathrm{p}<0.001\right)$.

SES differences in trends in smoking related outcomes (research question 2) were examined with the regression analyses described above for the survey years 2001 and 2008 taken together and with a dichotomous 'trends' variable (0 for 2001 and 1 for 2008) and the interaction between 'trends' and education/income level (separate analyses per SES indicator) as independent variables. Regression analyses were controlled for age group and reported separately for men and women. Education level and income level were treated as continuous variables in the interaction analyses so as to limit the number of interaction terms. In all other analyses, they were treated as categorical variables with high education level and income level being the reference categories. Significant interactions between 'trends' and education level or income level indicated that the trends in smoking related outcomes differed for people with low, moderate, and high SES.

\section{Results}

\section{Demographic characteristics}

Table 1 shows demographic characteristics of respondents per year. There were no significant differences in education level, gender, and age group between years. However, income level differed significantly between years $\left(\chi^{2}(14)=669.19, \mathrm{p}<0.001\right)$, which was due to an increase in respondents with higher incomes over time.

\section{SES inequalities}

Figure 1 shows education level differences and Figure 2 income level differences in smoking prevalence, consumption, initiation ratio, and quit ratio from 2001 to 2008. The figures show that smoking prevalence was higher among respondents with lower education (29\% in 2008 ) and income levels (28\%) than among respondents with higher education (20\%) and income levels (24\%). 
Table 1 Demographic characteristics from 2001 to 2008 (weighted data)

\begin{tabular}{|c|c|c|c|c|c|c|c|c|}
\hline & $\begin{array}{l}2001 \\
n=18,361\end{array}$ & $\begin{array}{l}2002 \\
n=18,212\end{array}$ & $\begin{array}{l}2003 \\
n=19,086\end{array}$ & $\begin{array}{l}2004 \\
n=18,342\end{array}$ & $\begin{array}{l}2005 \\
n=19,344\end{array}$ & $\begin{array}{l}2006 \\
n=18,031\end{array}$ & $\begin{array}{l}2007 \\
n=14,730\end{array}$ & $\begin{array}{l}2008 \\
n=18,627\end{array}$ \\
\hline \multicolumn{9}{|c|}{ Education level (\%) } \\
\hline Low & 44.4 & 44.5 & 44.4 & 44.5 & 44.4 & 44.5 & 44.5 & 44.5 \\
\hline Moderate & 33.6 & 33.6 & 33.6 & 33.6 & 33.6 & 33.6 & 33.6 & 33.6 \\
\hline High & 22.0 & 22.0 & 22.0 & 21.9 & 21.9 & 21.9 & 21.9 & 21.9 \\
\hline \multicolumn{9}{|c|}{ Income level (\%) } \\
\hline Low & 43.6 & 38.4 & 34.8 & 35.7 & 36.0 & 35.7 & 36.2 & 34.6 \\
\hline Moderate & 34.8 & 37.1 & 34.2 & 35.1 & 34.7 & 37.3 & 35.5 & 36.3 \\
\hline High & 21.5 & 24.6 & 31.0 & 29.2 & 29.2 & 27.0 & 28.3 & 29.2 \\
\hline \multicolumn{9}{|l|}{ Gender (\%) } \\
\hline Men & 49.1 & 49.1 & 49.1 & 49.2 & 49.1 & 49.1 & 49.1 & 49.0 \\
\hline Women & 50.9 & 50.9 & 50.9 & 50.8 & 50.9 & 50.9 & 50.9 & 51.0 \\
\hline \multicolumn{9}{|c|}{ Age group (\%) } \\
\hline $15-24$ & 14.7 & 14.7 & 14.7 & 14.7 & 14.7 & 14.7 & 14.7 & 14.7 \\
\hline $25-39$ & 29.9 & 30.3 & 30.3 & 30.6 & 30.3 & 30.3 & 30.7 & 30.8 \\
\hline $40-54$ & 26.9 & 26.5 & 26.5 & 26.3 & 26.4 & 26.5 & 26.1 & 26.0 \\
\hline 55 and older & 28.4 & 28.6 & 28.5 & 28.4 & 28.6 & 28.5 & 28.5 & 28.6 \\
\hline
\end{tabular}

The regression analyses shown in Table 2 confirmed that the difference in smoking prevalence between respondents with higher and lower education and income was significant among both men and women in 2001 and 2008.

Smoking consumption levels were significantly higher among lower educated respondents than among higher educated respondents among both men and women in 2001 and 2008. Differences in smoking consumption between respondents with higher and lower income were smaller and only significant among women in 2001 and 2008.

The difference in initiation ratios between respondents with higher and lower education and income was significant among both men and women in 2001 and 2008, indicating that lower SES respondents more often started smoking than higher SES respondents.

Finally, quit ratios were significantly higher among respondents with higher education and income than among respondents with lower education and income among both men and women in 2001 and 2008, with the exception of differences between male respondents with higher and lower income levels in 2001.

\section{Changes in SES inequalities}

Among women, educational differences changed significantly between 2001 and 2008 for smoking prevalence, smoking initiation, and smoking cessation (Table 3). Regression analyses stratified by education level showed that smoking prevalence did not change between 2001 and 2008 among female respondents with low education (Odds Ratio $(\mathrm{OR})=0.95,95 \%$ confidence interval $(\mathrm{CI})=0.86$ to 1.04), while smoking prevalence decreased among female respondents with moderate $(\mathrm{OR}=0.89,95 \% \mathrm{CI}=0.79$ to $0.99)$ and high education $(\mathrm{OR}=0.68,95 \% \mathrm{CI}=0.58$ to $0.80)$. Initiation ratios increased significantly among female respondents with low education $(\mathrm{OR}=1.19,95 \% \mathrm{CI}=1.09$ to 1.30), while remaining constant among female respondents with moderate $(\mathrm{OR}=1.04,95 \% \mathrm{CI}=0.94$ to 1.15$)$ and high education $(\mathrm{OR}=0.88,95 \% \mathrm{CI}=0.77$ to 1.01$)$. Quit ratios increased significantly among female respondents in all education levels, but the increase was larger among female respondents with high education $(\mathrm{OR}=1.60,95 \% \mathrm{CI}=$ 1.30 to 1.97$)$ than moderate $(\mathrm{OR}=1.21,95 \% \mathrm{CI}=1.05$ to $1.40)$ and low education $(\mathrm{OR}=1.16,95 \% \mathrm{CI}=1.03$ to 1.30$)$.

Among men, educational inequalities widened significantly between 2001 and 2008 for smoking consumption and not for smoking prevalence, initiation, and cessation (Table 3). The mean number of cigarettes per day did not change between 2001 and 2008 among male smokers with low education $(\beta=-0.03,95 \% \mathrm{CI}=-0.07$ to 0.01$)$, while the mean number of cigarettes per day decreased among male smokers with moderate $(\beta=-0.10,95 \% \mathrm{CI}=-0.15$ to $-0.06)$ and high education $(\beta=-0.08,95 \% \mathrm{CI}=-0.16$ to $-0.01)$.

Among both women and men, income differences in smoking related outcomes did not change significantly between 2001 and 2008 . 


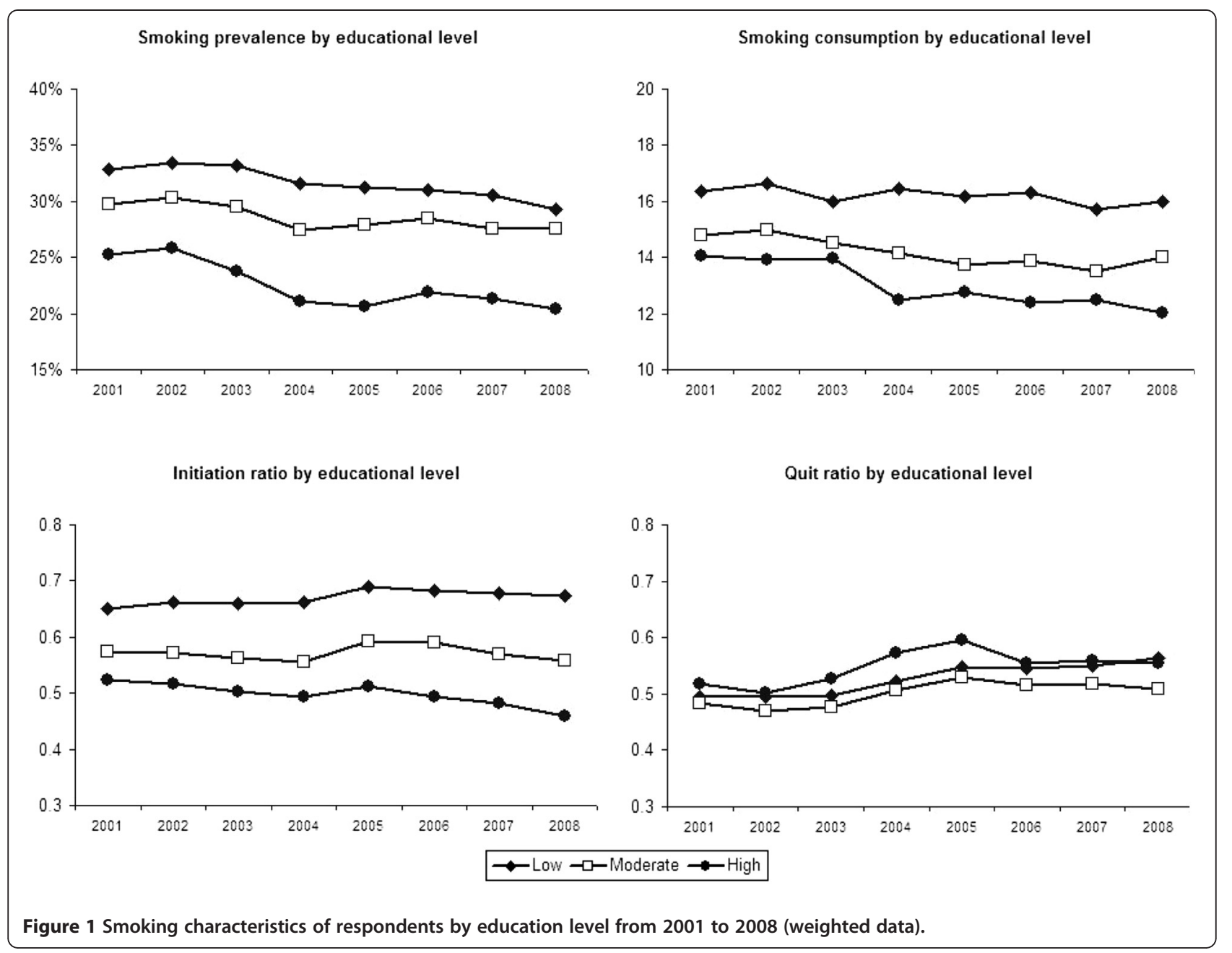

\section{Discussion}

We examined changes in socioeconomic inequalities in smoking prevalence, smoking consumption, smoking initiation, and smoking cessation between 2001 and 2008 in the Netherlands. In line with previous studies [7-16], we found that respondents with lower education and income were more likely to be smokers than respondents with higher education and income in 2001 and 2008. Socioeconomic inequalities in smoking consumption, smoking initiation, and smoking cessation are less well documented than inequalities in smoking prevalence [17]. We found that respondents with lower education smoked more cigarettes per day, had higher initiation ratios, and had lower quit ratios than respondents with higher education in 2001 and 2008. Therefore, it is important that tobacco control programs focus on decreasing smoking initiation and consumption and increasing smoking cessation among the lower educated. It seems that focusing only on either initiation or cessation is insufficient.
In this study, we found evidence that SES inequalities in smoking widened between 2001 and 2008 in the Netherlands, but this widening was not the same for women and men and it depended on which SES and smoking indicator was used. Among women, educational inequalities widened significantly for smoking prevalence, smoking initiation, and smoking cessation. Among men, educational inequalities widened significantly for smoking consumption. The widening pattern in smoking, initiation, and quitting among low educated women is especially worrying. In this group, smoking prevalence remained stable between 2001 and 2008 because both the initiation and quit ratio increased slightly. Among moderate and high educated women smoking prevalence decreased because initiation ratios remained constant, while quit ratios increased considerably. Other studies have also found that in countries in later stages of the smoking epidemic, SES inequalities in smoking prevalence are stable among men, while they are widening among women $[10,13]$. Also, it was found earlier that SES 


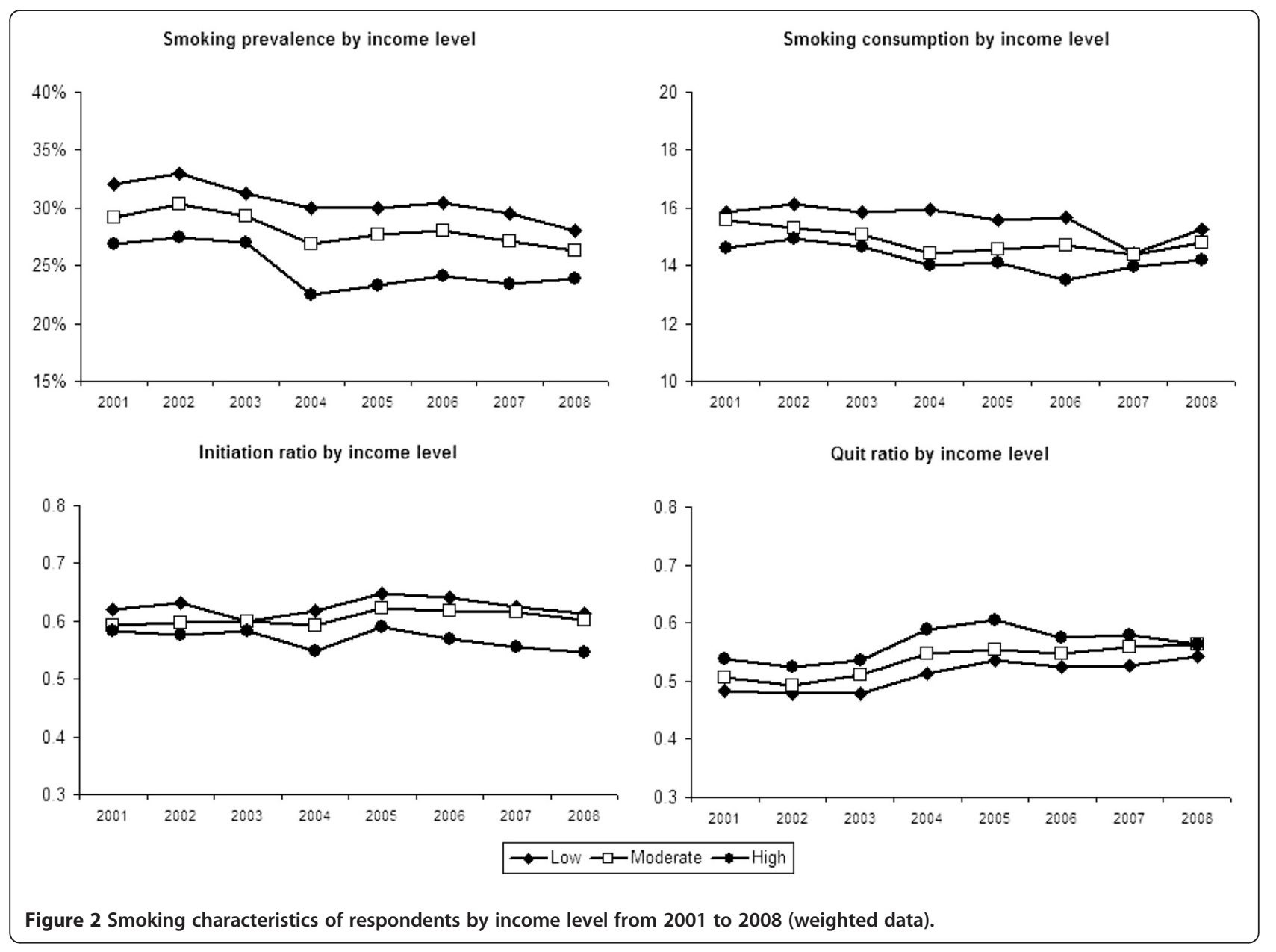

inequalities in smoking consumption are stable among women and widening among men [13].

According to the literature, advertising bans, smoking bans in workplaces, reimbursement of smoking cessation therapies, and increased tobacco taxes have the potential to reduce SES differences in smoking [25]. During our study period, smoke-free workplace legislation (2004), smoke-free hospitality industry legislation (2008), and tobacco tax increases (2001, 2004, and 2008) were implemented in the Netherlands. From our data, it looks like there was a change in SES inequalities in smoking prevalence and consumption between 2003 and 2004, when the smoke-free workplace legislation was implemented together with a tax increase. However, the SES inequalities seem to be widening instead of narrowing. An earlier study also showed that the workplace smoking ban in the Netherlands has increased SES differences in smoking cessation [22]. An explanation could be that the smoke-free legislation was not comprehensive: the hospitality industry was exempted (until 2008) and designated smoking rooms were allowed.
Our study had some important strengths. We used very large, representative samples of the Dutch population over a period of eight years. Therefore, changes in SES differences over time could be detected and generalized to the Dutch population. Also, we examined both education level and income level differences in four smoking related outcomes, including smoking initiation and cessation for both men and women. Our study thus provides a more detailed picture of SES differences in smoking than most studies. This study also had some limitations. First of all, we relied on self reported smoking status. Since there can be differences in underreporting of smoking between SES groups, this could have influenced our results. Second, income levels were unknown for $21 \%$ of respondents. These respondents were excluded from the analyses and this may have introduced selection bias. However, since we also used another SES indicator (education level) with only a few missing values resulting in comparable findings, we expect that the missing income data did not bias our results. Furthermore, we used initiation and quit ratios to estimate 
Table 2 Regression analysest in which education level and income level predicted four smoking related outcomes

\begin{tabular}{|c|c|c|c|c|}
\hline & \multicolumn{2}{|c|}{ Men } & \multicolumn{2}{|c|}{ Women } \\
\hline & 2001 & 2008 & 2001 & 2008 \\
\hline \multicolumn{5}{|c|}{ Smoking prevalence } \\
\hline \multicolumn{5}{|c|}{ Education level* } \\
\hline Low & $1.75(1.55$ to 1.97$)$ & 1.84 (1.62 to 2.09 ) & 1.79 (1.56 to 2.06$)$ & 2.26 (1.96 to 2.62 ) \\
\hline Moderate & $1.32(1.17$ to 1.49$)$ & 1.44 (1.27 to 1.64$)$ & 1.25 (1.09 to 1.44$)$ & 1.62 (1.41 to 1.87 ) \\
\hline High & 1.00 & 1.00 & 1.00 & 1.00 \\
\hline \multicolumn{5}{|l|}{ Income level } \\
\hline Low & 1.33 (1.17 to 1.51$)$ & 1.49 (1.31 to 1.70$)$ & 1.52 (1.33 to 1.74 & 1.83 (1.58 to 2.10$)$ \\
\hline Moderate & 1.13 (0.99 to 1.28$)$ & 1.11 (0.98 to 1.25$)$ & $1.12(0.97$ to 1.30$)$ & 1.39 (1.20 to 1.60$)$ \\
\hline High & 1.00 & 1.00 & 1.00 & 1.00 \\
\hline
\end{tabular}

\section{Smoking consumption}

Education level

\begin{tabular}{|c|c|c|c|c|}
\hline Low & 0.11 (0.06 to 0.17 ) & 0.17 (0.11 to 0.23 ) & 0.11 (0.05 to 0.17$)$ & 0.20 (0.13 to 0.26$)$ \\
\hline Moderate & 0.07 (0.02 to 0.13$)$ & 0.07 (0.01 to 0.13 ) & $0.01(-0.05$ to 0.07$)$ & 0.12 (0.06 to 0.18 ) \\
\hline High & 0.00 & 0.00 & 0.00 & 0.00 \\
\hline \multicolumn{5}{|l|}{ Income level } \\
\hline Low & 0.06 (0.00 to 0.11$)$ & $0.00(-0.06$ to 0.06$)$ & 0.12 (0.06 to 0.17 ) & 0.15 (0.08 to 0.20 ) \\
\hline Moderate & $0.05(-0.01$ to 0.11$)$ & $-0.01(-0.06$ to 0.04$)$ & 0.06 (0.00 to 0.12 ) & 0.08 (0.02 to 0.14$)$ \\
\hline High & 0.00 & 0.00 & 0.00 & 0.00 \\
\hline
\end{tabular}

\section{Initiation ratio}

Education level

$\begin{array}{lllll}\text { Low } & 1.87(1.66 \text { to } 2.10) & 2.24(1.99(2.52) & 1.41(1.25 \text { to } 1.59) & 1.73(1.53 \text { to } 1.95) \\ \text { Moderate } & 1.43(1.27 \text { to } 1.61) & 1.47(1.30 \text { to } 1.65) & 1.19(1.05 \text { to } 1.34) & 1.45(1.29 \text { to } 1.63) \\ \text { High } & 1.00 & 1.00 & 1.00 & 1.00 \\ \text { Income level } & & 1.51(1.32 \text { to } 1.73) & 1.25(1.11 \text { to } 1.41) & 1.32(1.17 \text { to } 1.49) \\ \text { Low } & 1.32(1.16 \text { to } 1.51) & 1.27(1.13 \text { to } 1.43) & 1.01(0.89 \text { to } 1.14) & 1.21(1.08 \text { to } 1.37) \\ \text { Moderate } & 1.14(1.00 \text { to } 1.30) & 1.00 & 1.00 & 1.00\end{array}$

\section{Quit ratio}

Education level

$\begin{array}{lllll}\text { Low } & 0.81(0.70 \text { to } 0.94) & 0.84(0.71 \text { to } 0.98) & 0.69 \text { (0.58 to } 0.82) & 0.56(0.47 \text { to } 0.67) \\ \text { Moderate } & 0.95(0.81 \text { to } 1.11) & 0.83(0.70 \text { to } 0.98) & 0.92 \text { (0.77 to } 1.10) & 0.73(0.61 \text { to } 0.87) \\ \text { High } & 1.00 & 1.00 & 1.00 & 1.00 \\ \text { hcome level } & & 0.76(0.64 \text { to } 0.89) & 0.72(0.61 \text { to } 0.85) & 0.56(0.47 \text { to } 0.66) \\ \text { Low } & 0.86(0.74 \text { to } 1.01) & 1.05(0.91 \text { to } 1.22) & 0.88(0.74 \text { to } 1.05) & 0.78(0.66 \text { to } 0.92) \\ \text { Moderate } & 0.96(0.82 \text { to } 1.13) & 1.00 & 1.00 & 1.00 \\ \text { High } & 1.00 & & \end{array}$

† Odds Ratios and 95\% confidence intervals are given for smoking prevalence, initiation ratio, and quit ratio, Bètas and $95 \%$ confidence intervals for smoking consumption. All regression coefficients were adjusted for age group. Regression coefficients in italics were non-significant.

* Education level and income level were entered as independent variables in separate analyses.

population level smoking initiation and cessation. These ratios may not be sensitive enough to reflect short term changes in smoking initiation and cessation. However, initiation and quit ratios are suitable for understanding long term population trends [17].

\section{Conclusion}

This study exemplifies that inequalities in smoking prevalence among women and smoking consumption among men may widen in the fourth stage of the smoking epidemic. Although our study provides some insight in trends 
Table 3 Interactionst of trends by education level and income level on four smoking related outcomes

\begin{tabular}{lll}
\hline & Men & Women \\
\hline Smoking prevalence & & \\
Trends * education level & $0.99(0.91$ to 1.07$)$ & $0.86(0.79$ to 0.94$)$ \\
Trends * income level & $0.95(0.87$ to 1.04$)$ & $0.94(0.86$ to 1.04$)$ \\
\hline Smoking consumption & & \\
Trends * education level & $-0.08(-0.17$ to -0.01$)$ & $-0.04(-0.13$ to 0.04$)$ \\
Trends * income level & $0.05(-0.04$ to 0.14$)$ & $-0.02(-0.11$ to 0.07$)$ \\
\hline Initiation ratio & & \\
Trends * education level & $0.94(0.87$ to 1.02) & $0.86(0.79$ to 0.92) \\
Trends * income level & $0.92(0.84$ to 1.01) & $0.97(0.90$ to 1.06)
\end{tabular}

\section{Quit ratio}

Trends * education level $\quad 0.99$ (0.90 to 1.10$) \quad 1.14(1.02$ to 1.28$)$

Trends * income level $\quad 1.05$ (0.94 to 1.18) 1.11 (0.99 to 1.25$)$

† Odds Ratios and 95\% confidence intervals are given for smoking prevalence, initiation ratio, and quit ratio, Bètas and $95 \%$ confidence intervals are given for smoking consumption. All regression coefficients were adjusted for age group. Regression coefficients in italics were non-significant.

* Education level and income level were entered as independent variables in separate analyses.

in SES differences in smoking in populations, more research is needed to find ways to successfully address these differences. While inequalities in smoking prevalence were stable among Dutch men, they increased among women, due to widening inequalities in both smoking cessation and initiation. Therefore, both components should be addressed in equity-oriented tobacco control policies.

\section{Abbreviations}

SES: Socioeconomic status; DCSSH: Dutch Continuous Survey of Smoking Habits.

\section{Competing interests}

The authors declare that they have no competing interests.

\section{Acknowledgements}

The Dutch Continuous Survey of Smoking Habits was supported by grants from the Dutch Ministry of Health, Welfare and Sport. This paper is an adaptation of a Dutch report from STIVORO, which has been written with contributions from Dianne de Korte-de Boer, Gera Nagelhout, Regina van der Meer, Tarquínia Zeegers, Boukje van Gelder, and Marc Willemsen. We thank Dagmar Feenstra for her contributions with data cleaning.

\section{Author details}

${ }^{1}$ STIVORO Dutch Expert Centre on Tobacco Control, PO Box 16070, 2500 BB, The Hague, the Netherlands. ${ }^{2}$ Maastricht University (CAPHRI), Maastricht, the Netherlands. ${ }^{3}$ Academic Medical Centre, University of Amsterdam, Amsterdam, the Netherlands. ${ }^{4}$ National Institute for Public Health and the Environment (RIVM), Bilthoven, the Netherlands.

\section{Authors' contributions}

GN conducted the statistical analyses and wrote the manuscript. All other authors advised on the writing of the manuscript. GN, DdK, RvdM, TZ, BvG, and MW were involved in a Dutch report of which this paper is an adaptation. AK and HdV advised on the design of the study and the statistical analyses. All authors read and approved the final manuscript.

Received: 3 February 2012 Accepted: 26 April 2012

Published: 26 April 2012

\section{References}

1. Mackenbach JP, Bos V, Andersen O, Cardano M, Costa G, Harding S, Reid A, Hemström Ö, Valkonen T, Kunst AE: Widening socioeconomic inequalities in mortality in six Western European countries. Int J Epidemiol 2003, 32:830-837.

2. Blais C, Hamel D, Rinfret S: Impact of socioeconomic deprivation and area of residence on access to coronary revascularization and mortality after a first acute myocardial infarction in Québec. Can J Cardiol 2012, 28(2):169-177.

3. Saydah S, Lochner K: Socioeconomic Status and Risk of Diabetes-Related Mortality in the U.S. Public Health Reports 2010, 125:377-388.

4. Strand BH, Tverdal A: Can cardiovascular risk factors and lifestyle explain the educational inequalities in mortality from ischaemic heart disease and from other heart diseases? 26 year follow up of 50000 Norwegian men and women. J Epidemiol Community Health 2004, 58:705-709.

5. Stringhini S, Sabia S, Shipley M, Brunner E, Nabi H, Kivimaki M, Singh-Manoux A: Association of socioeconomic position with health behaviors and mortality. JAMA 2010, 303:1159-1166.

6. Lopez AD, Collishaw NE, Piha T: A descriptive model of the cigarette epidemic in developed countries. Tob Control 1994, 3:242-247.

7. Harper S, Lynch J: Trends in socioeconomic inequalities in adult health behaviors among U.S. states, 1990-2004. Public Health Rep 2007, 122:177-189.

8. Pierce JP, Fiore MC, Novotny TE, Hatziandreu EJ, Davis RM: Trends in cigarette smoking in the United States. Educational differences are increasing. JAMA 1989, 261:56-60.

9. Smith P, Frank J, Mustard C: Trends in educational inequalities in smoking and physical activity in Canada: 1974-2005. J Epidemiol Community Health 2009, 63:317-323.

10. Bennett S: Cardiovascular risk factors in Australia: trends in socioeconomic inequalities. J Epidemiol Community Health 1995, 49:363-372.

11. White V, Hill D, Siahpush M, Bobevski I: How has the prevalence of cigarette smoking changed among Australian adults? Trends in smoking prevalence between 1980 and 2001. Tob Control 2003, 12(Suppl 2):67-74.

12. Hill SE, Blakely TA, Fawcett JM, Howden-Chapman P: Could mainstream anti-smoking programs increase inequalities in tobacco use? New Zealand data from 1981-96. Aust N Z J Public Health 2005, 29:279-284.

13. Giskes K, Kunst AE, Benach J, Borrel C, Costa G, Dahl E, Dalstra JAA, Federico B, Helmert U, Judge K, Lahelma E, Moussa K, Ostergren PO, Platt S, Prattala R, Rasmussen NK, Mackenback JP: Trends in smoking behaviour between 1985 and 2000 in nine European countries by education. J Epidemiol Community Health 2005, 59:395-401.

14. Daponte-Codina A, Bolívar-Muñoz J, Ocaña-Riola R, Toro-Cárdenas S, Mayoral-Cortés J: Patterns of smoking according to individual social position, and to socio-economic environment in municipal areas, Spain 1987-2001. Health Place 2009, 15:709-716.

15. Rasmussen M, Due P, Damsgaard MT, Holstein BE: Social inequality in adolescent daily smoking: Has it changed over time? Scand J Public Health 2009, 37:287-294.

16. Osler M, Gerdes LU, Davidsen M, Brønnum-Hansen H, Madsen M, Jørgensen T, Schroll M: Socioeconomic status and trends in risk factors for cardiovascular diseases in the Danish MONICA population, 1982-1992. J J Epidemiol Community Health 2000, 54:108-113.

17. Schaap MM, Kunst AE: Monitoring of socio-economic inequalities in smoking: learning from the experiences of recent scientific studies. Public Health 2009, 123:103-109.

18. Federico B, Costa G, Kunst AE: Educational inequalities in initiation, cessation, and prevalence of smoking among 3 Italian birth cohorts. Am J Public Health 2007, 97:838-845.

19. Gilman SE, Abrams DB, Buka SL: Socioeconomic status over the life course and stages of cigarette use: Initiation, regular use, and cessation. $J$ Epidemiol Community Health 2003, 57:802-808.

20. U.S. Department of Health and Human Services. How tobacco smoke causes disease: The biology and behavioral basis for smoking-attributable disease: A report of the Surgeon General Atlanta, GA: U.S. Department of Health and Human Services, Centers for Disease Control and Prevention, National Center for Chronic Disease Prevention and Health Promotion, Office on Smoking and Health; 2010

21. Nagelhout GE, Levy DT, Blackman K, Currie L, Clancy L, Willemsen MC: The effect of tobacco control policies on smoking prevalence and smoking-attributable deaths. Findings from the Netherlands SimSmoke Tobacco Control Policy Simulation Model. Addiction 2012, 107:407-416. 
22. Nagelhout GE, Willemsen MC, De Vries $\mathrm{H}$ : The population impact of a workplace smoking ban and a hospitality industry smoking ban on smoking behaviour. Findings from a national population survey. Addiction 2011, 106:816-823.

23. Huisman $M$, Kunst AE, Mackenbach JP: Educational inequalities in smoking among men and women aged 16 years and older in 11 European countries. Tob Control 2005, 14:106-113.

24. Willemsen MC, Hoogenveen RT, van der Lucht F: New smokers and quitters. Transitions in smoking status in a national population. Eur $J$ Public Health 2002, 12:136-138.

25. Giskes K, Kunst AE, Ariza C, Benach J, Borrell C, Helmert U, Judge K, Lahelma E, Moussa K, Ostergren PO, Patja K, Platt S, Práttálá R, Willemsen MC, Mackenbach JP: Applying an equity lens to tobacco-control policies and their uptake in six Western-European countries. J Public Health Policy 2007, 28:261-280.

doi:10.1186/1471-2458-12-303

Cite this article as: Nagelhout et al:: Trends in socioeconomic inequalities in smoking prevalence, consumption, initiation, and cessation between 2001 and 2008 in the Netherlands. Findings from a national population survey. BMC Public Health 2012 12:303.

\section{Submit your next manuscript to BioMed Central and take full advantage of:}

- Convenient online submission

- Thorough peer review

- No space constraints or color figure charges

- Immediate publication on acceptance

- Inclusion in PubMed, CAS, Scopus and Google Scholar

- Research which is freely available for redistribution 